\title{
Potential prognostic value of delta-like protein 3 in small cell lung cancer: a meta- analysis
}

\author{
Benchao Chen, Heng Li, Chao Liu, Shuting Wang, Feiyue Zhang, Li Zhang, Mingjie Li and Gaofeng Li (D)
}

\begin{abstract}
Background: Current researches have revealed that delta-like protein 3 (DLL3) may be related with prognosis in patients with small cell lung cancer (SCLC). However, this finding remains controversial in small cell lung cancer. This meta-analysis was systematically performed to evaluate the prognostic value of DLL3 in SCLC.

Methods: The PubMed, EMBASE and Web of Science databases were retrieved to collect the eligible references. Through Stata 15.0 software, we pooled hazard ratios (HR) with 95\% confidence intervals (Cl) by using random or fixed-effects models to evaluate the association between DLL3 and SCLC survival results.

Results: A total of 6 inter-related studies including 645 patients were qualified. After we removed 1 study, the remaining 5 studies including 601 patients were pooled to testify that high expression of DLL3 was an inferior prognostic for patients with SCLC in Asian populations ( $\mathrm{HR}=1.37,95 \% \mathrm{Cl}=1.05,1.69 ; P^{2}=0.0 \%, p=0.000$ ). The pooled results showed that DLL3 might be higher expression in advanced metastasis SCLC in Asian populations (RR $\left.=0.84,95 \% \mathrm{Cl}=0.71,0.99 ; P^{2}=44.7 \%, p=0.039\right)$. But the expression of DLL3 was not correlated with sex (RR $=$ $\left.1.33,95 \% \mathrm{Cl}=0.98,1.80 ; P^{2}=0.0 \%, p=0.064\right)$, smoking history $\left(\mathrm{RR}=1.01,95 \% \mathrm{Cl}=0.58,1.75 ; P^{2}=72.1 \%, p=0.967\right)$ and tumour stage $\left(\mathrm{RR}=0.68,95 \% \mathrm{Cl}=0.44,1.05 ; P^{2}=66.6 \%, p=0.081\right)$.
\end{abstract}

Conclusions: Our meta-analysis confirms that in Asian populations, high expression of DLL3 was a potential poor prognostic biomarker for SCLC and DLL3 highly expressed in advanced stage SCLC in Asian populations.

Keywords: Delta-like protein 3, DLL3, Prognostic, Small cell lung cancer, SCLC, Meta-analysis

\section{Introduction}

Lung cancer has the highest morbidity and mortality of all malignant tumours, which is one of the most common cancers worldwide [1]. The major histologic subtypes of lung cancer are non-small cell lung cancer (NSCLC, 85\%) and small cell lung cancer (SCLC, 15\%) [2]. SCLC is an invasive, high-grade malignancy with early development and a bad prognosis. Most patients with SCLC are advanced with widespread metastasis when they are diagnosed, and systemic chemotherapy is

\footnotetext{
* Correspondence: ligaofengh|@126.com
}

Department of Thoracic Surgery, The Third Affiliated Hospital of Kunming

Medical University (Yunnan Cancer Hospital), Kunming, Yunnan, China the most effective therapy [3]. Few therapeutic methods are available after SCLC relapse, and the prognosis is especially poor. Therapeutic treatments for patients with SCLC have essentially remained unchanged in recent years [4]. Thus, further research into the mechanism of SCLC and the exploration of new therapeutic targets for SCLC is imperative.

Delta-like protein 3 (DLL3) is a transmembrane protein that promotes the development of neuroendocrine tumours through its reciprocity with the Notch pathway [5]. It is expressed in cancer tissues in approximately $85 \%$ of patients with SCLC and other neuroendocrine cancer but is not expressed in non-neuroendocrine 
tumours or normal tissues [6]. Most studies have shown that DLL3 is a latent treatment target point for SCLC [7-9]. Recently, many researches initiate to focus on the prognostic value of DLL3 in SCLC. Some of the researchers demonstrated that DLL3 had no correlation with prognosis in SCLC patients [10,11], but other investigators showed that DLL3 was associated with the survival of patients with SCLC [12]. So previous studies of the prognostic value of DLL3 in SCLC remain controversial, we performed this systematic meta-analysis for resolving this controversial.

Published articles discussing the prognostic value of DLL3 in SCLC were systematically reviewed in our meta-analysis. We aimed to include all correlational studies to assess the prognostic value of DLL3 and attempted to identify an accurate biomarker to guide prognosis and treatment for SCLC in the future.

\section{Methods}

\section{Search strategy}

The PRISMA guidelines were followed for our metaanalysis (see Additional file 1) [13]. The literatures were collected through retrieving the PubMed, EMBASE and Web of Science databases from the initial date to February 25,2020 . The search strategy was "DLL3 OR deltalike protein 3" (all fields) AND "non-small cell lung cancer OR NSCLC OR small cell lung cancer OR SCLC OR Lung Adenocarcinoma OR Lung Squamous cell carcinoma OR lung cancer OR lung tumour OR lung neoplasm OR lung carcinoma" (all fields). There was no limitation on the publication status. All eligible studies were retrieved, and the headlines and abstracts of all the reference lists of the reviews or studies were independently filtrated through three authors based on the criteria. Differences between two authors were resolved by the third author's opinions.

\section{Inclusion criteria}

Researches were included by following the standards: (1) studies reported the prognostic value of DLL3 in SCLC, (2) studies were published as original articles, (3) studies reported the data of HR and $95 \%$ CI or provided survival curve and (4) studies in which the prognostic value was investigated by survival analysis with overall survival (OS), disease-free survival (DFS), progression-free survival (PFS), relapse/recurrence-free survival (RFS) or disease-specific survival (DSS). We excluded the animal researches and other review literatures.

\section{Data extraction}

Two researchers independently extracted the data included the author, country, edition year, sample capacity, patients' sex, smoking history, distant metastasis, tumour stage, histologic subtype, biomarker(s), scoring methods, cut-offs value and the data of $\mathrm{HR}$ and 95\% CI. We extracted the multivariate analysis outcome if one study included both univariate and multivariate analysis outcomes. When we could not extract the data of HR and $95 \% \mathrm{CI}$ directly in the article but the survival curves were reported, we extracted and digitized the survival curves by operating the Engauge Digitizer software (http://digitizer.sourceforge.net/), and we estimated the data of $\mathrm{HR}$ and $95 \% \mathrm{CI}$ by the Excel programme files as exploited by Tierney et al. [14]. When the data of HR and survival curves were not reported, we contacted the corresponding authors of eligible articles by email to obtain the original data; these articles were excluded if there was no response.

\section{Assessment of study quality}

Two researchers independently used the Quality In Prognosis Studies (QUIPS) tool to assess risk of bias of all the publications [15]. According to the criteria, every article was evaluated as low risk, moderate risk or high risk by following six different areas: study participation, study attrition, prognostic factor measurement, outcome measurement, study confounding and statistical analysis and reporting [15]. Differences were settled through discussion.

\section{Statistical analysis}

Two authors independently extracted the HR and 95\% CI from the original articles. The HR was used to describe the high DLL3 expression versus low DLL3 expression. We took the reciprocal of the HR if the articles showed the low DLL3 expression vs. high DLL3 expression. We observed that high expression of DLL3 portended a worse prognosis when $\mathrm{HR}>1$ and that $\mathrm{HR}<1$ indicated preferable prognosis. For the analysis results, $p$ $<0.05$ was considered statistically significant. Statistical heterogeneity was assessed by calculating the $I^{2}$ statistic [16]. The presence of heterogeneity was indicated when $I^{2}>50 \%$, and then a random-effects model was applied to pool the results [17]; a fixed-effects model was employed to pool the results when $I^{2}<50 \%$ [18]. We performed further subgroup or sensitivity analysis to analyse the heterogeneity. The publication bias was estimated by Begg's and Egger's tests, when $p>0.05$ indicates no publication bias [19]. Through Stata 15.0 software, we performed this meta-analysis and acquired the forest plots.

\section{Results}

\section{Search results and study characteristics}

Using the searching strategy described above, a total of 140 original documents were identified from the databases, with approximately 74 studies remaining after excluding duplicates. After screening the titles and 
abstracts of the 74 publications, 58 publications were not related to evaluating the prognosis role of DLL3 in SCLC. Finally, we were left with 16 eligible studies after screening the full text, among which 6 articles were included in our final analysis (Fig. 1) [20-25]. Ten articles were excluded for the following reasons: seven articles were review researches and commentaries, one article did not report hazard ratios and Kaplan-Meier curves and 2 articles were abstracts and did not report relevant outcomes. The 6 eligible articles' characteristics are shown in Table 1. All these articles came out from the initial date to February 25, 2020, and the patients were diagnosed as SCLC by histopathology. Among these studies, all studies investigated DLL3 by immunohistochemistry (IHC) in paraffin-embedded tissue.

\section{Quality assessment of the included studies}

We performed quality evaluations of the 6 articles following the QUIPS tool, and two authors independently evaluated all the literature. Differences were resolved by discussion. After screening all included articles, we found that there were no researches that reported study attrition, and there were no standardization of cut-offs value for evaluating DLL3 expression. And then 3 studies were evaluated as low risk, 2 were evaluated as moderate risk and 1 study was evaluated as high risk (Table 2). This outcome indicated that most of the studies we included were of a medium or high quality.

\section{Prognostic value of DLL3 in SCLC}

As shown in Fig. 2, 6 eligible articles were pooled for analysing the prognostic value of DLL3 in SCLC. The

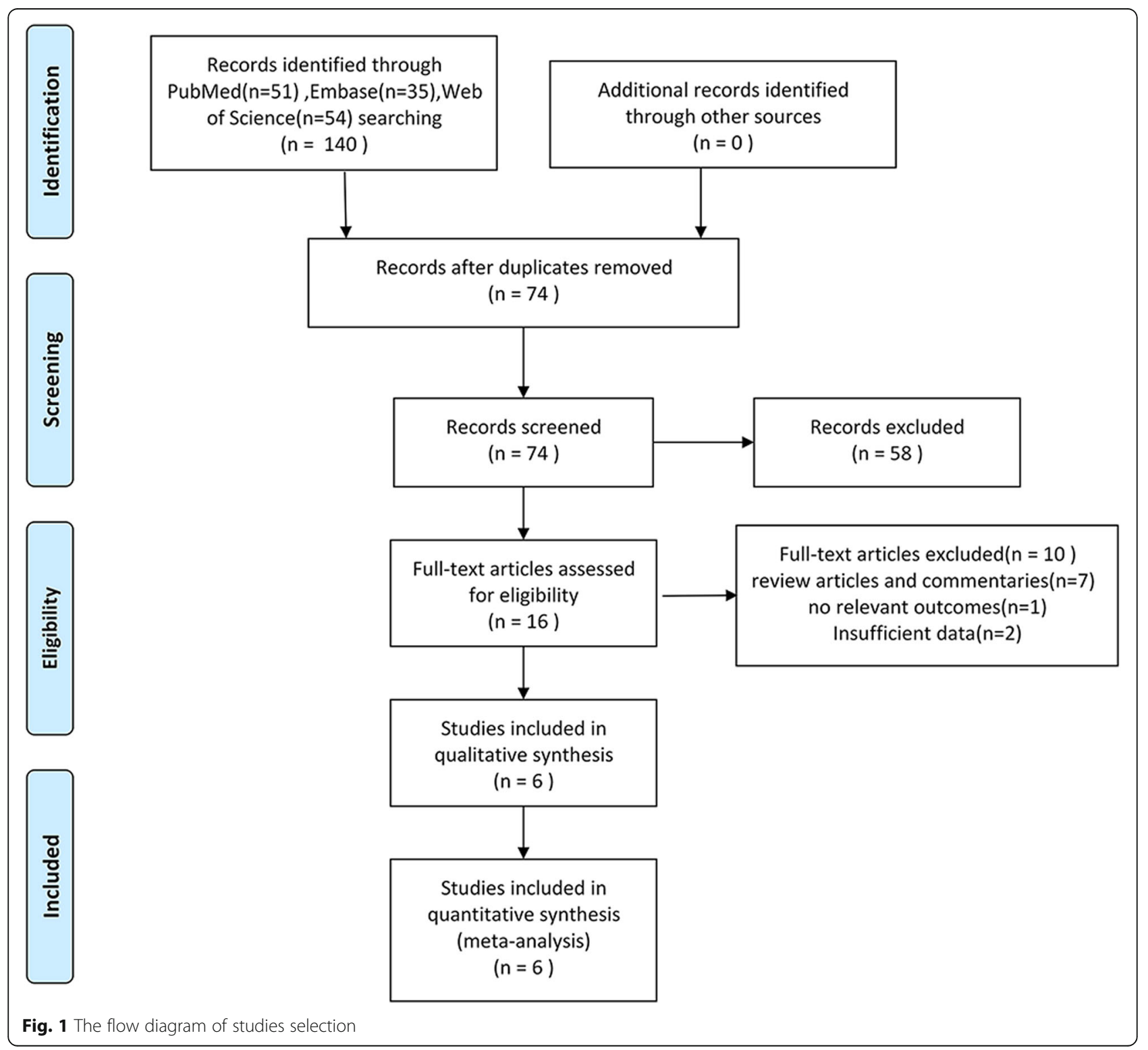


Table 1 Study characteristics of the 6 eligible articles

\begin{tabular}{|c|c|c|c|c|c|c|c|c|c|c|c|c|}
\hline Study & Year & Country & $\begin{array}{l}\text { No. of } \\
\text { samples }\end{array}$ & $\begin{array}{l}\text { Sex } \\
\text { (male/ } \\
\text { female) }\end{array}$ & $\begin{array}{l}\text { Smoking } \\
\text { history } \\
\text { (non/yes) }\end{array}$ & $\begin{array}{l}\text { Distant } \\
\text { metastasis } \\
\text { (negative/ } \\
\text { positive) }\end{array}$ & $\begin{array}{l}\text { Tumour } \\
\text { stage } \\
(|-|||||||-\mid V)\end{array}$ & $\begin{array}{l}\text { Histologic } \\
\text { subtype }\end{array}$ & Method & Outcomes & Biomarkers & $\begin{array}{l}\text { Cut-off } \\
\text { value }\end{array}$ \\
\hline Yan et al. [20] & 2019 & China & 335 & $306 / 29$ & $93 / 242$ & $165 / 170$ & $29 / 306$ & SCLC & $\mathrm{IHC}$ & OS & DLL3/TTF1 & score $\geq 150$ \\
\hline Xie et al. [21] & 2019 & USA & 44 & $19 / 25$ & N/A & N/A & $19 / 16$ & $\mathrm{SCLC}$ & $\mathrm{IHC}$ & OS & DLL3 & $\geq 50 \%$ \\
\hline Tanaka et al. [22] & 2018 & Japan & 63 & $52 / 11$ & $3 / 60$ & N/A & N/A & SCLC & $\mathrm{IHC}$ & OS & DLL3 & $\geq 50 \%$ \\
\hline $\begin{array}{l}\text { Regzedmaa } \\
\text { et al. [23] }\end{array}$ & 2019 & China & 38 & $26 / 12$ & $12 / 26$ & $15 / 23$ & $16 / 22$ & SCLC & $\mathrm{IHC}$ & OS & $\begin{array}{l}\text { DLL3/CTLA-4/ } \\
\text { MSTN }\end{array}$ & score $\geq 1$ \\
\hline Huang et al. [24] & 2019 & China & 72 & N/A & N/A & N/A & $\mathrm{N} / \mathrm{A}$ & $\mathrm{SCLC}$ & $\mathrm{IHC}$ & OS/PFS & DLL3 & score $\geq 6$ \\
\hline Furuta et al. [25] & 2019 & Japan & 93 & $72 / 21$ & $18 / 75$ & N/A & $82 / 11$ & SCLC & $\mathrm{HHC}$ & OS & DLL3/ASCL1 & $\geq 75 \%$ \\
\hline
\end{tabular}

SCLC small cell lung cancer, IHC immunohistochemistry, OS overall survival, PFS progression-free survival, DLL3 delta-like protein 3, CTLA-4 cytotoxic T lymphocyteassociated protein 4, MSTN mesothelin, ASCL1 achaete-scute homologue-1, N/A not applicable

results showed that high expression of DLL3 indicated no prognostic value in patients with SCLC $(\mathrm{HR}=1.13$, $\left.95 \% \mathrm{CI}=0.61,1.65 ; I^{2}=68.2 \%, p=0.008\right)$. However, prominent heterogeneity existed in the pooled results, so we conducted further subgroup analysis. Among the six studies, three articles were from China, two were from Japan and one was from America. We divided the studies into the Asian group and the American group for subgroup analysis. As shown in Additional file 2. Fig.A.1, we found that the heterogeneity was $0.0 \%$ in the Asian group, and we believed that the main cause of the heterogeneity was the study from American. So we decided to eliminate the study from American and only analysed the remained 5 studies. After we removed the American study, the outcomes indicated that high DLL3 expression was a poor prognosis marker in SCLC (HR $=1.37$, 95\% $\mathrm{CI}=1.05,1.69 ; I^{2}=0.0 \%, p=0.000$ ) (Fig. 3). Then, we divided the 5 studies into two groups according to the size of the sample, and the final outcomes indicated that high DLL3 expression was a poor prognosis marker in the group with sample size greater than $100(\mathrm{HR}=1.49$, $95 \% \mathrm{CI}=1.05,1.93, p=0.000$ ) (Fig. 4). But there was no significant relationship between DLL3 expression and prognosis in the group with sample size less than 100 $\left(\mathrm{HR}=0.99,95 \% \mathrm{CI}=0.45,1.54 ; I^{2}=53.7 \%, p=0.000\right)$ (Fig. 4). Begg's test $(p=0.624)$ and Egger's test $(p=$ 0.103) results demonstrated that there was no publication bias in our meta-analysis (Fig. 5). Finally, sensitivity analysis showed that all the studies were stable (see Additional file 2. Fig.A.6).

\section{The clinical characteristics of patients with DLL3 expression in SCLC}

The pooled results showed that the expression of DLL3 was not correlated with sex $(\mathrm{RR}=1.33,95 \% \mathrm{CI}=0.98$, 1.80; $I^{2}=0.0 \%, p=0.064$ ) (Table 3, Additional file 2 . Fig.A.2), smoking history $(\mathrm{RR}=1.01,95 \% \mathrm{CI}=0.58$, $1.75 ; I^{2}=72.1 \%, p=0.967$ ) (Table 3, Additional file 2 . Fig.A.3) and tumour stage ( $\mathrm{RR}=0.68,95 \% \mathrm{CI}=0.44$, 1.05; $I^{2}=66.6 \%, p=0.081$ ) (Table 3, Additional file 2 . Fig.A.4). But DLL3 was highly expressed in patients with distant metastasis $\left(\mathrm{RR}=0.84,95 \% \mathrm{CI}=0.71,0.99 ; I^{2}=\right.$ $44.7 \%, p=0.039$ ) (Table 3, Additional file 2. Fig.A.5).

\section{Discussion}

Many studies have shown that DLL3 played a significant prognosis value in patients with cancer. For example, high DLL3 expression was associated with shorter OS and PFS in small cell bladder cancer [26]. High DLL3 expression was associated with bad OS and usually expressed in older patients and advanced stage in endometrial cancer [27]. Xie et al. reported that high DLL3 expression predicted a better OS in patients with SCLC [21], and other studies foreboded that high DLL3

Table 2 Quality assessment of included studies

\begin{tabular}{|c|c|c|c|c|c|c|c|}
\hline Study & $\begin{array}{l}\text { Study } \\
\text { participation }\end{array}$ & $\begin{array}{l}\text { Study } \\
\text { attrition }\end{array}$ & $\begin{array}{l}\text { Prognostic factor } \\
\text { measurement }\end{array}$ & $\begin{array}{l}\text { Outcome } \\
\text { measurement }\end{array}$ & Study confounding & $\begin{array}{l}\text { Statistical analysis } \\
\text { and reporting }\end{array}$ & $\begin{array}{l}\text { Total risk } \\
\text { of bias }\end{array}$ \\
\hline Yan et al. [20] & 0 & $\bullet$ & $\circ$ & $\circ$ & $\circ$ & o & Low \\
\hline Xie et al. [21] & - & $\bullet$ & $\circ$ & $\circ$ & ○ & $\circ$ & Moderate \\
\hline Tanaka et al. [22] & $\circ$ & $\bullet$ & $\circ$ & $\circ$ & $\circ$ & $\circ$ & Low \\
\hline Regzedmaa et al. [23] & $\circ$ & $\bullet$ & $\circ$ & $\circ$ & ○ & $\circ$ & Low \\
\hline Huang et al. [24] & $\circ$ & $\bullet$ & $\circ$ & 0 & $\bullet$ & $\circ$ & High \\
\hline Furuta et al. [25] & ○ & $\bullet$ & $\circ$ & $\circ$ & ○ & $\circ$ & Moderate \\
\hline
\end{tabular}

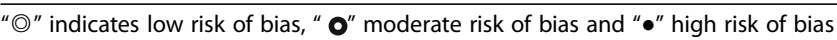




Study
LI-XU YAN (2019)

expression was an inferior prognostic marker for SCLC $[20,23]$. Thus, the results of different studies remained controversial. We included a total of 5 studies with 601 patients with SCLC to assess the prognostic value of DLL3 in SCLC by pooling the data of HR and 95\% CI.
First, we performed this meta-analysis using 6 studies. But heterogeneity was observed in our pooled results. Through further subgroup analysis, we found that a study from the American was the main cause of heterogeneity. As we removed the American study, we found

\begin{tabular}{|c|c|c|c|}
\hline Study & & $\mathrm{HR}(95 \% \mathrm{Cl})$ & Weight(\%) \\
\hline & $\begin{array}{l}1 \\
1 \\
1\end{array}$ & & \\
\hline LI-XU YAN (2019) & $\mid \begin{array}{c}1 \\
-1 \\
1 \\
1 \\
1\end{array}$ & $1.49(1.11,1.99)$ & 53.19 \\
\hline Kentaro Tanaka (2018) & $\left\{\begin{array}{c}1 \\
1 \\
1 \\
1\end{array}\right.$ & $0.98(0.48,1.98)$ & 18.31 \\
\hline Orgilmaa Regzedmaa (2019) & $\begin{array}{l}1 \\
1 \\
1 \\
1 \\
1\end{array}$ & $-3.40(1.34,8.60)$ & 0.78 \\
\hline MEGUMI FURUTA (2019) & $\frac{1}{1}$ & $1.55(0.84,2.88)$ & 9.90 \\
\hline Jianling Huang (2019) & -1 & $1.21(0.67,2.19)$ & 17.83 \\
\hline Overall $(I-$ squared $=0.0 \%, p=0.585)$ & $\left(\begin{array}{l}1 \\
1 \\
1\end{array}\right)$ & $1.37(1.05,1.69)$ & 100.00 \\
\hline$T$ & 4 & \multicolumn{2}{|l|}{ 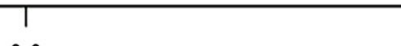 } \\
\hline-8.6 & 1 & \multicolumn{2}{|l|}{8.6} \\
\hline
\end{tabular}




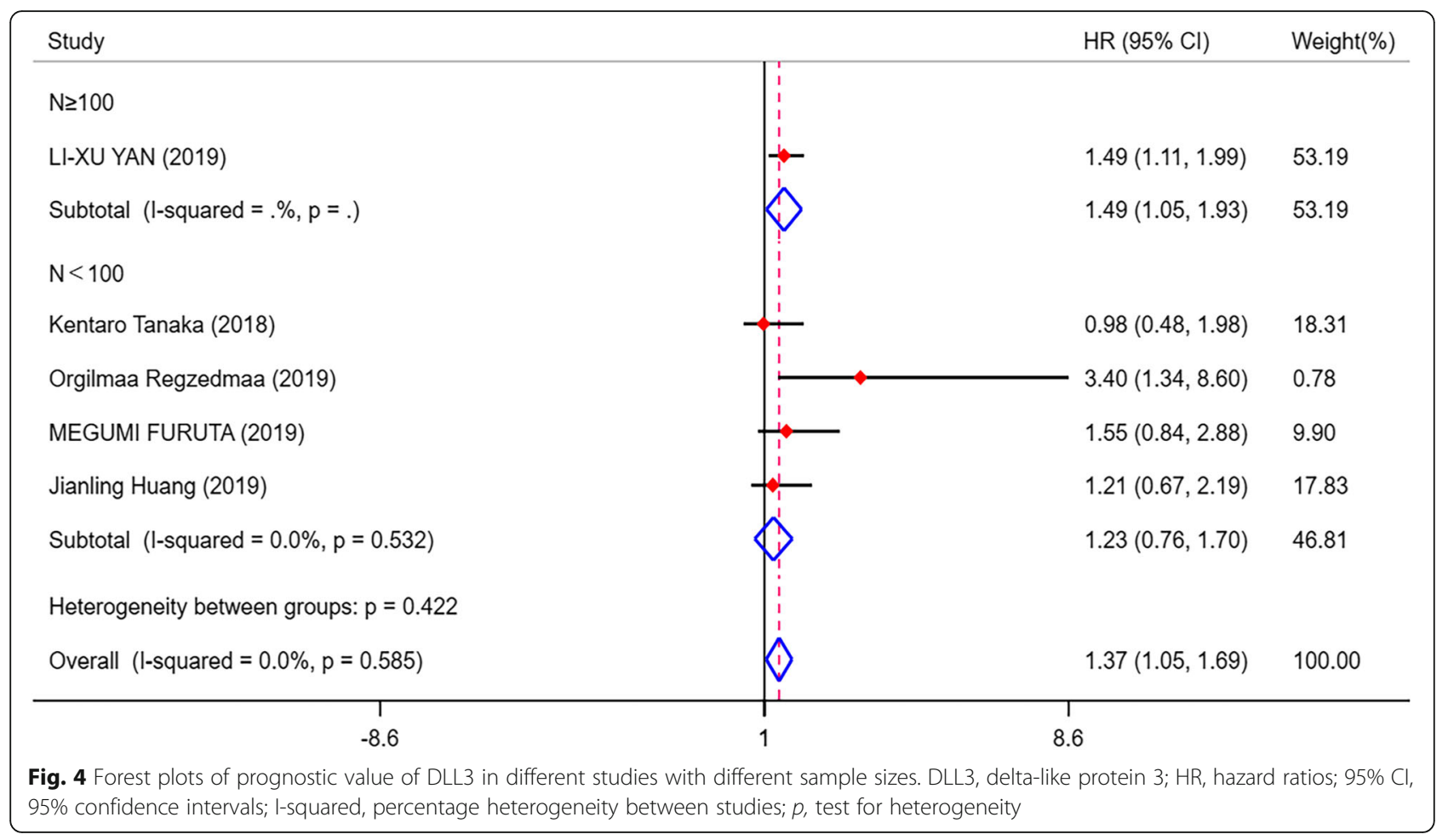

that high expression of DLL3 is a marker of poor prognosis in SCLC. But we also noticed that the results of the American study were contrary to our conclusions, they reported that high expression of DLL3 is a marker of good prognosis in SCLC. One interpretation of this result was that DLL3 expression varies between different populations. The American study indicated that the high expression of DLL3 was a marker of good prognosis [21], and there was no significant correlation between DLL3 expression and prognosis in several Japan studies $[22,25]$, while the high expression of DLL3 is a marker of poor prognosis in China studies [20,23]. These results showed that the expression of DLL3 might be different in different populations. However, only one study

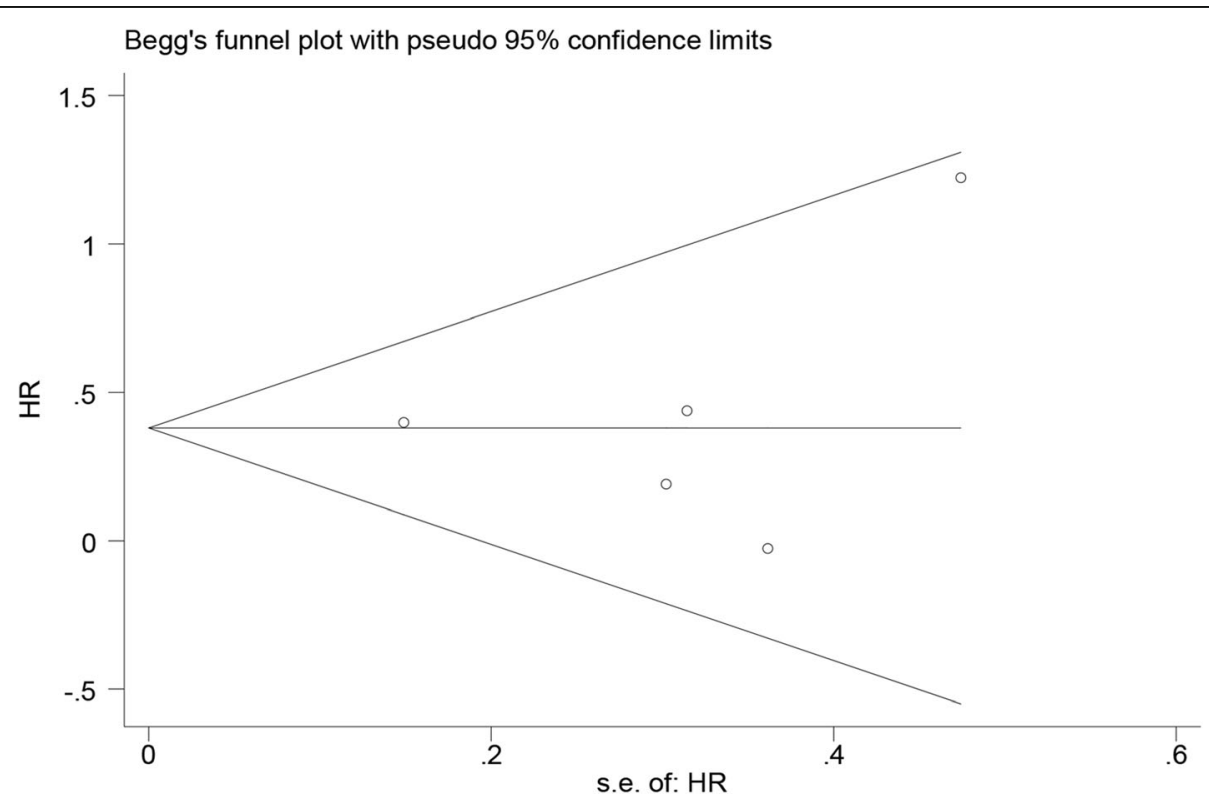

Fig. 5 Funnel plot of DLL3 present on overall survival. DLL3, delta-like protein 3; HR, hazard ratios 
Table 3 Summary of the correlation between DLL3 expression and the clinical characteristics of patients with SCLC

\begin{tabular}{lllll}
\hline Clinical characteristics & No. of studies & $P^{2}(p)$ & RR $(95 \%$ Cl) & $P$ value \\
\hline Sex (male/female) & 3 & $0.0 \%(0.798)$ & $1.33(0.98,1.80)$ & 0.064 \\
Smoking history(non/yes) & 3 & $72.1 \%(0.028)$ & $1.01(0.58,1.75)$ & 0.967 \\
Distant metastasis (negative/positive) & 2 & $44.7 \%(0.179)$ & $0.84(0.71,0.99)$ & 0.039 \\
Tumour stage (I-I/III-IV) & 3 & $66.6 \%(0.050)$ & $0.68(0.44,1.05)$ & 0.081 \\
\hline
\end{tabular}

SCLC small cell lung cancer, $R R$ relative ratios, $95 \%$ Cl 95\% confidence intervals, DLL3 delta-like protein $3, l^{2}$ percentage heterogeneity between studies, $p$ test for heterogeneity

researched the correlation with DLL3 expression and prognosis in SCLC outside of Asia, so the results need to be treated with caution. In addition, more studies were suggested for the future to further verify the existence of such differences.

Our other explanation of this result was that the expression of DLL3 was the same in different populations. Among the included studies, the sample size of 5 studies was less than 100, including the America and Japan studies. Therefore, we speculated that insufficient sample size might cause bias in the results. We conducted a subgroup analysis according to the sample size, and the results showed that the high expression of DLL3 in the studies with large sample sizes $(N \geq 100)$ was associated with poor prognosis, while the pooled results of the studies with low sample sizes $(N<100)$ showed no significant correlation between the expression of DLL3 and prognosis. Therefore, the sample size may be one of the reasons for the differences in DLL3 expression in each study. Moreover, immunohistochemistry was used to detect DLL3 expression in all of the studies. Immunohistochemical staining is a semi-quantitative method and is evaluated with great subjectivity [28]. Different antibodies and different cut-off values for DLL3 expression were employed in all the included studies and thus could also be another cause of the differences in results. The American study also explained their different results by claiming that many of the other studies were performed using mRNA expression instead of protein expression or used different cut-offs value of DLL3 expression [21].

Researches have reported that DLL3 is highly expressed in SCLC $[29,30]$, which suggested that DLL3 might promote the development of SCLC. Therefore, we also discussed the correlation between DLL3 expression and the clinical characteristics of patients with SCLC. The pooled results showed that DLL3 expression had no significant correlation with patients' sex, smoking status and stage, while DLL3 often highly expressed in metastasis patients of SCLC. Our survival analysis outcomes were consistent with this result, which suggested that high expression of DLL3 might be one of the factors contributing to poor prognosis in patients with advanced metastatic SCLC in Asia. However, only a few studies reported the correlation between the expression of DLL3 and clinical characteristics, and the methods and cutoffs values used to detect the DLL3 expression in each study were not uniform. Therefore, more reliable studies are needed to further verify our outcomes. Our results suggest that it is valuable to further investigate the correlation between DLL3 and the clinical characteristics of patients with SCLC.

Our meta-analysis is the first to focus on the prognostic value of DLL3 in SCLC. The significance of this meta-analysis lies in providing a basic direction and evidence for further research into the mechanism of DLL3 in SCLC. For SCLC, Notch1 over expression could induce G1 cell cycle arrest [31]. Previous studies reported that DLL3 downregulated the Notch receptor expression, thereby the Notch signalling pathway was inhibited within the cell [32]. Therefore, high expression of DLL3 can promote the development of SCLC by inhibiting the Notch signalling pathway. Studies also have shown that the high expression of DLL3 may reduce the sensitivity of chemotherapy drugs [24]. These studies have demonstrated that DLL3 may be associated with the prognosis of SCLC and also consistent with our meta-analysis results. Thus, studies of the corresponding targeted drugs of DLL3 can effectively inhibit the expression of DLL3 and thus improve the survival of SCLC. Rovalpituzumab tesirine (Rova-T) is a new antibody-drug conjugate directed against DLL3 in SCLC [33]. A phase I trial found that patients with high DLL3 expression in SCLC showed a better response to Rova- $\mathrm{T}$ than those with a low DLL3 expression [34]. However, disappointingly, the phase III TAHOE trial has been stopped because the Rova-T group showed a worse OS compared to the control group [35]. But more clinical trials are recruiting participator to investigate Rova- $\mathrm{T}$ as maintenance therapy in advanced stage SCLC. The lack of progress with this drug does not prevent us from making a breakthrough with other similar drugs. Some researches found that the intra-tumoural and inter-tumoural distribution of DLL3 protein in SCLC is homogeneous [20], supporting the conclusion that biopsy specimens are a reliable source for DLL3 evaluation for targeted therapy. In addition, most studies have demonstrated that DLL3 is 
highly expressed in SCLC, while it is not or is less expressed in other types of lung cancer and normal tissues [36]. Therefore, the expression of DLL3 can be detected by biopsy as an indicator for diagnosis, predicting therapeutic efficacy and monitoring recurrence or metastasis of SCLC in the future.

Although our study fully explains the prognostic value of DLL3 in SCLC, our analysis still has several limitations. First, large heterogeneity was observed in the pooled results. This is explained by the observation that the evaluation criteria for the expression of DLL3 are particularly mixed, and there are no international standards for cut-offs values to determine the expression of DLL3. Thus, the scoring methods and cut-offs values of DLL3 should be unified to strengthen our conclusions. Otherwise, the detection method of DLL3 in most studies is mainly immunohistochemistry at present, which is a semi-quantitative, subjective and inaccurate detection method. Different studies show different prognostic values of DLL3. Therefore, we need other more precise detection methods to evaluate the expression of DLL3 in SCLC in the future.

Second, the therapy method is also a key limitation. The current studies only focus on tissue specimens from patients with SCLC after surgery or biopsy, and few studies reported the treatment methods in their researches. However, the prognostic value of DLL3 may lie in the therapeutic method. Therefore, every study should pay attention to the impact of patient treatment methods on prognosis in the future.

Third, some of the original studies did not report the data of $\mathrm{HR}$ and $95 \% \mathrm{CI}$. The HR and 95\% CI results were measured from survival curves, an evaluation method with certain deviation and subjectivity, which might influence the authenticity of the results.

\section{Conclusion}

In summary, our meta-analysis confirmed that high expression of DLL3 was a potential poor prognostic biomarker for SCLC in Asian populations; moreover, DLL3 expression was correlated with advanced metastasis SCLC in Asian populations. However, the relationship between DLL3 expression and the prognostic or clinical characteristics of patients with SCLC in European and American populations need to be further verified. Thus, detecting the expression of DLL3 in tumour tissue will be helpful to guide therapy in Asian patients of SCLC. For our research, other high-quality studies, especially from European and American countries, are required to confirm our findings about the prognosis value of DLL3 in SCLC in the future. In view of the limitations of our analysis, the conclusions should be interpreted with caution.

\section{Supplementary information}

Supplementary information accompanies this paper at https://doi.org/10. 1186/s12957-020-02004-5.

\section{Additional file 1. The PRISMA checklist.}

Additional file 2: Fig.A.1. Forest plots of prognostic value of $D L L 3$ in SCLC. SCLC(small cell lung cancer), HR(hazard ratios), 95\% CI (95\% confidence intervals), DLL3(delta-like protein 3), $P^{2}$ (percentage heterogeneity between studies), $p$ (test for heterogeneity. Fig.A.2. Forest plots of the correlation between DLL3 expression and sex of patients with SCLC. SCLC(small cell lung cancer), RR(relative ratios), 95\% Cl (95\% confidence intervals), DLL3(delta-like protein 3), $P^{2}$ (percentage heterogeneity between studies), $p$ (test for heterogeneity). Fig.A.3. Forest plots of the correlation between DLL3 expression and smoking history of patients with SCLC. SCLC(small cell lung cancer), RR(relative ratios), 95\% Cl (95\% confidence intervals), DLL3(delta-like protein 3), $P^{2}$ (percentage heterogeneity between studies), $p$ (test for heterogeneity). Fig.A.4. Forest plots of the correlation between DLL3 expression and tumour stage of patients with SCLC. SCLC(small cell lung cancer), RR(relative ratios), 95\% Cl (95\% confidence intervals), DLL3(delta-like protein 3), $I^{2}$ (percentage heterogeneity between studies), $p$ (test for heterogeneity). Fig.A.5. Forest plots of the correlation between DLL3 expression and metastasis of patients with SCLC. SCLC(small cell lung cancer), RR(relative ratios), 95\% $\mathrm{Cl}$ (95\% confidence intervals), DLL3(delta-like protein 3), I $^{2}$ (percentage heterogeneity between studies), $p$ (test for heterogeneity). Fig.A.6.

Sensitivity analysis of all the studies.

\section{Abbreviations}

Cl: Confidence intervals; DLL3: Delta-like protein 3; DFS: Disease-free survival; DSS: Disease-specific survival; HR: Hazard ratios; IHC: Immunohistochemistry; OS: Overall survival; PFS: Progression-free survival; QUIPS: Quality In Prognosis Studies; RFS: Relapse/recurrence-free survival; RR: Risk ratio; SCLC: Small cell lung cancer

\section{Acknowledgements}

Not applicable.

\section{Authors' contributions}

All authors contributed to the study conception and design. Material preparation, data collection and analysis were performed by Benchao Chen, Heng Li and Chao Liu. The first draft of the manuscript was written by Benchao Chen and all authors commented on previous versions of the manuscript. All authors read and approved the final manuscript.

Authors' information

Not applicable.

\section{Funding}

This work was supported by the National Natural Science Foundation of China [No. 81760554].

Availability of data and materials

The datasets used and/or analysed during the current study are available from the corresponding author on reasonable request.

Ethics approval and consent to participate

Not applicable.

Consent for publication

Not applicable.

\section{Competing interests}

The authors declare that they have no competing interests.

Received: 8 July 2020 Accepted: 17 August 2020

Published online: 26 August 2020

\section{References}

1. Bray F, Ferlay J, Soerjomataram I, Siegel RL, Torre LA, Jemal A. Global cancer statistics 2018: GLOBOCAN estimates of incidence and mortality worldwide 
for 36 cancers in 185 countries. CA Cancer J Clin. 2018. https://doi.org/10. 3322/caac.21492.

2. Amini A, Byers LA, Welsh JW, Komaki RU. Progress in the management of limited-stage small cell lung cancer. Cancer. 2014;120(6). https://doi.org/10. 1002/cncr.28505

3. Mead GM, Arnold AM, Green JA, Williams CJ, Whitehouse JM. SMALL-CELL LUNG CANCER[]]. Cancer Chemother Pharmacol. 1980;315(8162):252. https:// doi.org/10.1016/S0140-6736(80)90733-3.

4. Powell HA, Tata LI, Baldwin DR, Potter VA, Stanley RA, Khakwani A, et al. Treatment decisions and survival for people with small-cell lung cancer. Br J Cancer. 2014;110(4):908-15. https://doi.org/10.1038/bjc.2013.812.

5. Huang RSP, Holmes BF, Powell C, Marati RV, Tyree D, Admire B, et al. Deltalike protein 3 prevalence in small cell lung cancer and DLL3 (SP347) assay characteristics. Arch Pathol Lab Med. 2019;143(11):1373-7. https://doi.org/10. 5858/arpa.2018-0497-OA.

6. Morgensztern D, Besse B, Greillier L, Santana-Davila R, Ready N, Hann CL, et al. Efficacy and safety of rovalpituzumab tesirine in third-line and beyond patients with DLL3-expressing, relapsed/refractory small-cell lung cancer: results from the phase II TRINITY study. Clin Cancer Res. 2019;25(23):695866. https://doi.org/10.1158/1078-0432.CCR-19-1133.

7. Isobe $Y$, Sato K, Nishinaga Y, Takahashi K, Taki S, Yasui H, et al. Near infrared photoimmunotherapy targeting DLL3 for small cell lung cancer. EBioMedicine. 2020;52:102632. https://doi.org/10.1016/j.ebiom.2020.102632.

8. Rossi A. Rovalpituzumab tesirine and DLL3: a new challenge for small-cell lung cancer. Lancet Oncol. 2017;18(1):3-5. https://doi.org/10.1016/s14702045(16)30575-7.

9. Rudin CM, Pietanza MC, Bauer TM, Ready N, Morgensztern D, Glisson BS, et al. Roval pituzumab tesirine, a DLL3-targeted antibody-drug conjugate, in recurrent small-cell lung cancer: a first-in-human, first-in-class, open-label, phase 1 study. Lancet Oncol. 2017;18(1):42-51. https://doi.org/10.1016/ s1470-2045(16)30565-4

10. Fu X, Tian T, Liu M, Ruan Z, Liang X, Nan K, et al. The expression and prognostic roles of PD-L1, PAPR1 and DLL3 in small cell lung cancer. J Thorac Oncol. 2019;14(10):S1024-5. https://doi.org/10.1016/j.jtho.2019.08.2267.

11. Lim S, Hong M, Kim SP, Chung SH. P2. 12-18 Prevalence of DLL3 Expression and its prognostic role in extensive stage small cell lung cancer. J Thorac Oncol. 2019;14(10):S820. https://doi.org/10.1016/j.jtho.2019.08.1763.

12. Poirier JT. Targeting DLL3 in small-cell lung cancer with novel modalities. J Thorac Oncol. 2020;15(2):S8. https://doi.org/10.1016/j.jtho.2019.12.024.

13. Liberati A, Altman DG, Tetzlaff J, Mulrow C, Gøtzsche PC, loannidis JPA, et al. The PRISMA statement for reporting systematic reviews and meta-analyses of studies that evaluate health care interventions: explanation and elaboration. J Clin Epidemiol. 2009;62(10):e1-e34. https://doi.org/10.1016/j. jclinepi.2009.06.006.

14. Tierney JF, Stewart LA, Ghersi D, Burdett S, Sydes MR. Practical methods for incorporating summary time-to-event data into meta-analysis. Trials. 2007; 8(1):16. https://doi.org/10.1186/1745-6215-8-16

15. Jill A, Hayden D, van der Windt DA, Cartwright JL, Côté P, Bombardier C. Assessing bias in studies of prognostic factors. Ann Int Med. 2013;158:280-6. https://doi.org/10.7326/0003-4819-158-4-201302190-00009.

16. Higgins TJP. Measuring inconsistency in meta-analyses. BMJ. 2003;327(7414): 557-60. https://doi.org/10.1136/bmj.327.7414.557.

17. Dersimonian R, Nan L. Meta-analysis in clinical trials. Control Clin Trials. 1986; 7(3):177-88. https://doi.org/10.1016/0197-2456(86)90046-2.

18. Mengersen KL, Tweedie RL, Biggerstaff B. The impact of method choice on meta-analysis. Aust N Z J Stat. 2008;37(1):19-44. https://doi.org/10.1111/j. 1467-842X.1995.tb00869.x.

19. Ahmed I, Sutton AJ, Riley RD. Assessment of publication bias, selection bias, and unavailable data in meta-analyses using individual participant data: a database survey. BMJ. 2012;344(7838):d7762. https:/doi.org/10.1136/bmj.d776.

20. Yan LX, Liu YH, Li Z, Luo DL, Li YF, Yan JH, et al. Prognostic value of deltalike protein 3 combined with thyroid transcription factor- 1 in small-cell lung cancer. Oncol Lett. 2019;18(3):2254-61. https://doi.org/10.3892/ol.2019.10538.

21. Xie H, Boland JM, Maleszewski JJ, Aubry MC, Yi ES, Jenkins SM, et al. Expression of delta-like protein 3 is reproducibly present in a subset of small cell lung carcinomas and pulmonary carcinoid tumors. Lung Cancer. 2019; 135:73-9. https://doi.org/10.1016/j.lungcan.2019.07.016.

22. Tanaka K, Isse K, Fujihira T, Takenoyama M, Saunders L, Bheddah S, et al. Prevalence of delta-like protein 3 expression in patients with small cell lung cancer. Lung Cancer. 2018;115:116-20. https://doi.org/10.1016/j.lungcan. 2017.11.018
23. Regzedmaa O, Li Y, Li Y, Zhang H, Wang J, Gong H, et al. Prevalence of DLL3, CTLA-4 and MSTN expression in patients with small cell lung cancer. Onco Targets Ther. 2019;12:10043-55. https://doi.org/10.2147/OTT.S216362.

24. Huang J, Cao D, Sha J, Zhu X, Han S. DLL3 is regulated by LIN28B and miR518d-5p and regulates cell proliferation, migration and chemotherapy response in advanced small cell lung cancer. Biochem Biophys Res Commun. 2019;514(3):853-60. https://doi.org/10.1016/j.bbrc.2019.04.130.

25. Furuta M, Sakakibara-Konishi J, Kikuchi H, Yokouchi H, Nishihara H, Minemura $\mathrm{H}$, et al. Analysis of DLL3 and ASCL1 in surgically resected small cell lung cancer (HOT1702). Oncologist. 2019;24(11):e1172-9. https://doi.org/ 10.1634/theoncologist.2018-0676.

26. Koshkin VS, Elson P, Magi-Galluzzi C, McKenney J, Smith KS, Shadrach B, et al. Prognostic value of DLL3 expression and clinicopathologic features in small cell bladder cancer (SCBC). J Clin Oncol. 2017;35(6):382.

27. Juan, Wang, Kaishuo, Zhang, Zi, Liu, et al. Upregulated delta-like protein 3 expression is a diagnostic and prognostic marker in endometrial cancer: a retrospective study. Medicine (Baltimore). 2018;97(51):e13442. https://doi. org/10.1097/MD.0000000000013442.

28. Matos LLD, Stabenow E, Tavares MR, Ferraz AR, Capelozzi VL, Pinhal MADS Immunohistochemistry quantification by a digital computer-assisted method compared to semiquantitative analysis. Clinics. 2006;61(5):417-24. https://doi.org/10.1590/S1807-59322006000500008.

29. Hann CL, Morgensztern D, Dowlati A, Burns TF, Jotte RM, Pennell NA, et al. A study of rovalpituzumab tesirine in frontline treatment of patients with DLL3 expressing extensive small cell lung cancer. J Clin Oncol. 2017;35. https://doi.org/10.1200/JCO.2017.35.15_suppl.TPS2598.

30. Furuta M, Sakakibara JK, Shoji T, Takashima Y, Kikuchi H, Kikuchi E, et al. DLL3 regulates migration and invasion of small cell lung cancer. Cancer Res. 2018;78(13). https://doi.org/10.1158/1538-7445.Am2018-3158.

31. Sriuranpong V, Borges MW, Ravi RK, Arnold DR, Nelkin BD, Baylin SB, et al. Notch signaling induces cell cycle arrest in small cell lung cancer cells. Cancer Res. 2001;61 (7):3200. https://doi.org/10.1097/00002820-200104000-00012.

32. Deng SM, Yan XC, Liang L, Wang L, Liu Y, Duan JL, et al. The Notch ligand delta-like 3 promotes tumor growth and inhibits Notch signaling in lung cancer cells in mice. Biochem Biophys Res Commun. 2017;483(1):488-94. https://doi.org/10.1016/j.bbrc.2016.12.117.

33. Komarnitsky P, Lee H, Shah M, Wong S, Gulbranson S, Dziubinski J, et al. Rovalpituzumab tesirine vs topotecan in patients with advanced small cell lung cancer following 1st line chemotherapy. J Thorac Oncol. 2017;12(11): S1974-5.

34. Udagawa H, Akamatsu H, Tanaka K, Takeda M, Kanda S, Kirita K, et al. Phase I safety and pharmacokinetics study of rovalpituzumab tesirine in Japanese patients with advanced, recurrent small cell lung cancer. Lung Cancer. 2019; 135:145-50. https://doi.org/10.1016/j.lungcan.2019.07.025.

35. Komarnitsky P, Lee HJ, Shah M, Wong S, Gulbranson S, Dziubinski J, et al. A phase 3 trial of rovalpituzumab tesirine vs topotecan in patients with advanced small cell lung cancer following frontline platinumbased chemotherapy. Ann Oncol. 2017;28:v542. https://doi.org/10.1093/annonc/ $m d \times 386.009$.

36. Odashiro P, Tomarchio G, Gagne A, Orain M, Desmeules P, Joubert P. DLL3 expression in small cell lung carcinomas (SCLC). Mod Pathol. 2020;33(SUPPL 2):1809-10.

\section{Publisher's Note}

Springer Nature remains neutral with regard to jurisdictional claims in published maps and institutional affiliations.

Ready to submit your research? Choose BMC and benefit from:

- fast, convenient online submission

- thorough peer review by experienced researchers in your field

- rapid publication on acceptance

- support for research data, including large and complex data types

- gold Open Access which fosters wider collaboration and increased citations

- maximum visibility for your research: over $100 \mathrm{M}$ website views per year

At BMC, research is always in progress.

Learn more biomedcentral.com/submissions 